\title{
Connections of the Medial Telencephalic Wall in the Spotted African Lungfish
}

\author{
R. Glenn Northcutt ${ }^{a}$ Guido Westhoff ${ }^{b}$ \\ aLaboratory of Comparative Neurobiology, Scripps Institution of Oceanography, and Department of

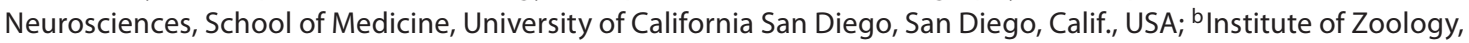 \\ University of Bonn, Poppelsdorfer Schloss, Bonn, Germany
}

\section{Key Words}

Forebrain · Hypothalamus - Lobe-finned fishes - Medial pallium $\cdot$ Septal nuclei

\begin{abstract}
The extent and boundaries of the roof, or pallium, of the telencephalon in lungfishes have been debated for over 30 years, and two hypotheses exist. Proponents of a restricted pallium claim that the medial border of the pallium occurs in a dorsal position and that the entire medial hemispheric wall is formed by the septal nuclei. Proponents of an extended pallium claim that the medial border of the pallium occurs in a more ventral position and that the medial hemispheric wall is divided into a dorsal medial pallium and ventral septal nuclei, as in amphibians. Immunohistochemical data have generally been interpreted to support the hypothesis of an extended pallium, but disagreement still exists. To clarify the extent of the pallium in lungfishes, the connections of the dorsal and ventral divisions of the medial hemispheric wall in the Spotted African Lungfish were examined using a number of neuronal tracers. In amphibians and other tetrapods, the afferent projections to the medial pallium and the septal nuclei differ extensively, as do the commissural routes taken by decussating interhemispheric connections. Although the
\end{abstract}

descending projections of the medial pallium and septal nuclei are very similar to one another in amphibians and other tetrapods, they do differ in that the septal nuclei and the ventral thalamus are extensively interlinked, whereas the medial pallium lacks such connections. These differences also characterize the connections of the dorsal and ventral divisions of the medial hemispheric wall in the Spotted African Lungfish, which supports the hypothesis of an extended pallium. The telencephalic organization in lungfishes thus appears remarkably similar to that in amphibians and reflects a pattern that almost certainly existed in the last common ancestor of lungfishes and tetrapods.

Copyright $\odot 2011$ S. Karger AG, Basel

\section{Introduction}

Lungfishes are believed to be the group of living lobefinned fishes most closely related to amphibians and other tetrapods [Brinkmann et al., 2004; Takezaki et al., 2004]. A number of descriptions of their brain organization exist [Holmgren and van der Horst, 1925; Gerlach, 1933; Nieuwenhuys, 1998; Northcutt, 2009], but there is no consensus regarding the number and extent of telencephalic cell groups in these fishes. One of the major dif-

\section{KARGER \\ Fax +4161306 1234 \\ E-Mail karger@karger.ch}

www.karger.com (c) 2011 S. Karger AG, Basel

0006-8977/11/0771-0014\$38.00/0

Accessible online at:

www.karger.com/bbe
R. Glenn Northcutt

Neurosciences 0201

University of California San Diego

La Jolla, CA 92093-0201 (USA)

Tel. +1 858534 5612, Fax +1 858534 5622, E-Mail rgnorthcutt@ucsd.edu 
ferences in interpretation relates to the position of the border between the medial pallium and the subpallium. There are presently two hypotheses regarding the homologies of the cell groups that form the medial telencephalic wall of lungfishes: (1) the restricted pallium hypothesis, and (2) the extended pallium hypothesis (fig. 1). Proponents of the restricted pallium hypothesis [Elliot Smith, 1908; Holmgren and van der Horst, 1925; Gerlach, 1933; Rudebeck, 1945; von Bartheld et al., 1990; Nieuwenhuys, 1998] believe that the medial pallial-subpallial border occurs high on the medial wall and that the entire telencephalic wall is homologous to the septum in other vertebrates (fig. 1C). In contrast, the proponents of the extended pallium hypothesis [Schnitzlein and Crosby, 1967; Clairambault and Capanna, 1973; Reiner and Northcutt,
1987; González and Northcutt, 2009; Northcutt, 2009] believe that the medial telencephalic wall in lungfishes, like that in other vertebrates with evaginated forebrains, can be divided into a dorsally situated medial pallium and a more ventrally situated septum (fig. 1D).

These hypotheses - like all hypotheses regarding homology - can be tested by determining the degree of similarity in position, in immunohistochemistry, including developmental genetic markers, in connections, and in continuity across taxa [Northcutt, 1984, 1995]. At present, the criteria of topology and continuity can be interpreted to support either the restricted or the extended pallium hypothesis. Although the immunohistochemical data [Reiner and Northcutt, 1987; González and Northcutt, 2009; Northcutt, 2009] most parsimoniously

\begin{tabular}{|c|c|c|c|}
\hline \multicolumn{4}{|c|}{ Abbreviations used in this paper } \\
\hline $\mathrm{a}$ & cerebellar auricle & mot & medial olfactory tract \\
\hline ac & anterior commissure & $\mathrm{mp}$ & medial pallium \\
\hline ad & dorsal tegmental nucleus & $\mathrm{mV}$ & mesencephalic trigeminal nucleus \\
\hline aob & accessory olfactory bulb & ncb & cerebellar nucleus \\
\hline at & anterior dorsal thalamus & $\mathrm{ob}$ & olfactory bulb \\
\hline bst & bed nucleus of the stria terminalis & ot & optic tectum \\
\hline c & cerebellum & otr & optic tract \\
\hline $\mathrm{ca}$ & central amygdalar nucleus & pa & anterior periventricular preoptic area \\
\hline $\mathrm{cl}$ & cortical layer & pal & pallidum \\
\hline $\mathrm{ct}$ & caudal dorsal thalamus & pc & pallial commissure \\
\hline $\mathrm{d}$ & diencephalon & pco & posterior commissure \\
\hline fr & fasciculus retroflexus & sc & supracommissural nucleus \\
\hline gl & glomerular layer of the olfactory bulb & $\mathrm{scn}$ & subcommissural pretectal nucleus \\
\hline hco & habenular commissure & sco & subcommissural organ \\
\hline ig & internal granular layer of the olfactory bulb & sep & septum \\
\hline ipl & internal plexiform layer of the olfactory bulb & $\sin$ & superficial isthmal nucleus \\
\hline jen & juxtacommissural pretectal nucleus & sr & superior raphe \\
\hline la & lateral amygdalar nucleus & st & rostral dorsal striatum \\
\hline lc & locus coeruleus & std & dorsal subdivision of the dorsal striatum \\
\hline ldt & laterodorsal tegmental nucleus & stv & ventral subdivision of the dorsal striatum \\
\hline let & lateral ependymal thickening & $\mathrm{sV}$ & trigeminal sensory tract \\
\hline lfb & lateral forebrain bundle & tel & telencephalon \\
\hline $\mathrm{lp}$ & lateral pallium & ts & torus semicircularis \\
\hline
\end{tabular}


Fig. 1. Alternate hypotheses regarding the extent of the pallium (A-D) in the Spotted African Lungfish (A). A transverse section, stained with cresyl violet, through the telencephalic hemisphere (B), reveals that most neuronal cell bodies are located in a periventricular position, except for those located in the dorsal portion of the medial wall, where there is considerable neuronal migration. In the restricted pallium hypothesis (C), the dorsomedial wall has been interpreted as a dorsal septal nucleus, whereas in the extended pallium hypothesis (D), it is interpreted as the medial pallium. Scale bar $=5 \mathrm{~mm}$.

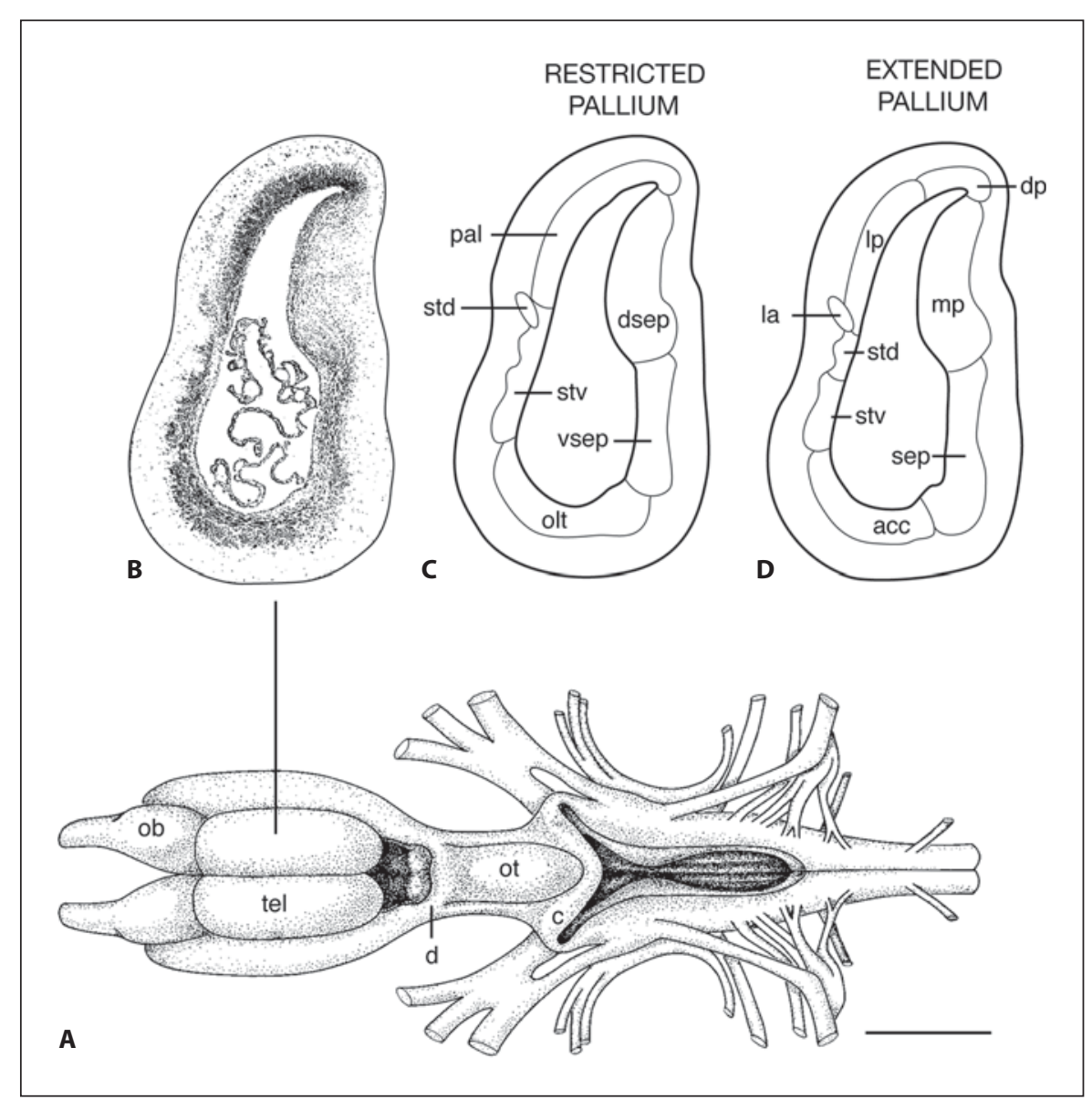

support the extended pallium hypothesis, this interpretation has been questioned [von Bartheld et al., 1990]. For this reason, the connections of the putative medial pallium and septal nuclei of the Spotted African Lungfish have been examined using a number of different tracers.

In amphibians, which are believed to be the closest living relatives of lungfishes, the connections of the medial pallium [Neary, 1990; Northcutt and Ronan, 1992; Westhoff and Roth, 2002; Roth et al., 2007] and septal nuclei [Neary and Northcutt, 1990; Endepols et al., 2005; Roden et al., 2005] have been extensively examined experimentally, and there are a number of distinct differences in the connections of these 2 cell groups that allow them to be easily distinguished from one another. Comparison of the connections of the putative medial pallium and the septal nuclei of the Spotted African Lungfish with those of the medial pallium and septal nuclei of amphibians supports the extended pallium hypothesis regarding the organization of the medial telencephalic wall of lungfishes.

\section{Materials and Methods}

Juvenile Spotted African Lungfish, Protopterus dolloi, were obtained from commercial dealers. The animals were $27-42 \mathrm{~cm}$ in total length and were maintained in aquaria at $27-29^{\circ} \mathrm{C}$. All procedures were approved by the UCSD Animal Care and Use Committee and conform to NSF guidelines.

\section{Cytoarchitectonics}

Six animals were anesthetized by immersion in $0.01 \%$ tricaine methanesulfonate solution and perfused with $0.1 \mathrm{M}$ phosphate buffer ( $\mathrm{PB}, \mathrm{pH}$ 7.4), followed by a solution of $4 \%$ paraformaldehyde in $0.1 \mathrm{M} \mathrm{PB}$. The brains were removed from the skulls and postfixed for $12 \mathrm{~h}$ to 5 days. They were then washed, dehydrated, embedded in Paraplast (Oxford Labware, St. Louis, Mo., USA), and cut at $15 \mu \mathrm{m}$ in the 3 standard anatomical planes. The serial sections were stained with cresyl violet (N4) or by the Bodian method (N2) to visualize the cytoarchitecture of the different brain cell groups and their associated fiber tracts.

\section{Experimental Procedures}

The 44 experimental cases involved injection of either biotinylated dextran amine (BDA, 10,000 MW), biocytin, or the carbocyanine dye $\mathrm{DiI}$ into various brain areas. The number of injec- 
Table 1. Lungfish experimental cases

\begin{tabular}{|c|c|c|c|c|c|}
\hline \multirow[t]{2}{*}{ Case } & \multicolumn{2}{|l|}{ BDA } & \multirow[t]{2}{*}{ Biocytin } & \multirow[t]{2}{*}{ DiI } & \multirow[t]{2}{*}{ Days } \\
\hline & in vitro & in vivo & & & \\
\hline Olfactory bulb & & 6 & & & 8,10 \\
\hline Lateral pallium & & & & 1 & 21 \\
\hline Medial pallium & 2 & 4 & 2 & 3 & $2-7,14,21,35$ \\
\hline Septal nuclei & & & 2 & 5 & $2,4,14,21,35$ \\
\hline Striatum & & & 2 & 4 & $2,4,14,21,35$ \\
\hline Habenular nuclei & & & & 1 & 21 \\
\hline Dorsal thalamus & 1 & 1 & & 3 & $5,21,35$ \\
\hline Ventral thalamus & & & & 2 & 14,21 \\
\hline Preoptic area & & & & 1 & 21 \\
\hline Hypothalamus & & & & 2 & 35,42 \\
\hline Posterior tubercle & & & & 2 & 21,35 \\
\hline
\end{tabular}

tions made into each brain area, the tracer used, and the experimental time frame are listed in table 1. Although the focus of the study was to determine the connections of the putative medial pallium and the septal nuclei, a substantial number of other brain centers listed in table 1 were injected as reciprocal experiments to facilitate the distinction of afferent versus efferent connections of the medial telencephalic wall, and to confirm that the brain centers exhibiting retrogradely labeled cell bodies did, in fact, project to either the medial pallium or to septal nuclei.

The BDA experiments involved both in vitro and in vivo cases, and BDA (Invitrogen, Eugene, Oreg., USA) was injected as either a concentrated paste on the tip of an insect pin or by iontophoresis. In the in vitro cases, the animals were anesthetized in a tricaine methanesulfonate solution $(0.01 \%)$ and perfused with cold (4$\left.6^{\circ} \mathrm{C}\right)$ oxygenated Ringer's solution $\left(\mathrm{Na}^{+} 100 \mathrm{mM}, \mathrm{K}^{+} 2 \mathrm{mM}, \mathrm{Ca}^{2+}\right.$ $2 \mathrm{mM}, \mathrm{Mg}^{2+} 0.5 \mathrm{mM}^{-\mathrm{Cl}^{-}} 82 \mathrm{mM}, \mathrm{HCO}_{3}{ }^{-} 25 \mathrm{~mm}$, glucose $\left.11 \mathrm{mM}\right)$ at $\mathrm{pH}$ 7.3. The brains were removed quickly via a ventral approach through the roof of the oropharynx and pinned in petri dishes filled with cold oxygenated Ringer's solution. A ring-shaped silver wire was placed on the dorsal surface of the telencephalon as the reference electrode and sharpened glass micropipettes filled with $7-11 \%$ of BDA diluted in $0.3 \mathrm{M} \mathrm{KCl}$ were the active electrodes. The micropipettes had a resistance of $0.2-3 \mathrm{M}^{\prime} \Omega$ and were driven into the dorsomedial telencephalic wall. A positive constant current of 2-5 $\mu$ A was applied for $20 \mathrm{~min}$ for iontophoretic injection of BDA. The brains were then stored for 5 days in cold, oxygenated Ringer's solution which was changed daily. Subsequently, the brains were fixed by immersion in a mixture of buffered $2 \%$ glutaraldehyde and $2 \%$ paraformaldehyde for $2 \mathrm{~h}$. The brains were then washed in $\mathrm{PB}$ for $12 \mathrm{~h}$ and embedded in agar, and $50 \mu \mathrm{m}$ transverse sections were cut on a vibratome. The freely floating sections were treated with $0.5 \% \mathrm{H}_{2} \mathrm{O}_{2}$ for 15 min to reduce endogenous peroxidase activity, rinsed three times in $\mathrm{PB}$, and incubated for $2 \mathrm{~h}$ in an avidin-biotin complex (Vectastain, ABC Standard Kit; Vector Laboratories, Burlinghame, Calif., USA) and 0.5\% Triton X-100 (Sigma, St. Louis, Mo., USA) using diaminobenzidine (DAB) as a chromogen intensified with heavy metal following the protocol of Adams [1981]. The sections were then counterstained with $1 \%$ cresyl violet, dehydrated, and coverslipped.

Lungfish Medial Telencephalic Connections
In the in vivo BDA cases, the animals were anesthetized with tricaine methanesulfonate solution $(0.01 \%)$, the skin reflected, and the muscle overlying the forebrain retracted. The underlying dermal bone was then removed and the meninges opened to expose either the olfactory bulb, the telencephalic hemispheres, or the diencephalon. In the case of the olfactory bulbs, a unilateral injection of concentrated BDA paste on the tip of an insect pin was placed in several places within the olfactory bulb. In the case of the medial pallium, BDA was iontophoretically injected in the same manner as the in vitro injections. In the case of the dorsal thalamus, concentrated BDA paste on the tip of an insect pin was placed into the dorsal thalamus lateral to the habenula in a single insertion. The exposed part of the brain was then covered with Gelfoam (Upjohn, Kalamazoo, Mich., USA) saturated with saline solution, and the skin flap was replaced and sealed in place with Vetbond (3M, St. Paul, Minn., USA). The animals were revived in running water and allowed to survive for times ranging from 5 to 10 days, after which the animals were reanesthetized, perfused, and the brains processed as in the in vitro BDA experiments.

All biocytin (Invitrogen, Eugene, Oreg., USA) injections were conducted in vitro. The animals were anesthetized by immersion in $0.01 \%$ tricaine methanesulfonate solution and perfused in cold $\left(4-6^{\circ} \mathrm{C}\right)$, oxygenated Ringer's solution for $5 \mathrm{~min}$. The brains were quickly removed from the skull and the meninges removed from the region of the brain that was to be injected. Crystals of biocytin were then inserted into a specific brain region with an insect pin, and the brain was placed in fresh, oxygenated Ringer's solution and stored at $4^{\circ} \mathrm{C}$. The solution was changed daily with freshly oxygenated Ringer's solution. Following incubation for 2 days, the brains were fixed by immersion in a $4 \%$ solution of buffered paraformaldehyde for $24 \mathrm{~h}$. The brains were then rinsed in PB and embedded in a sucrose-gelatin mixture. The blocked brains were fixed in a buffered sucrose-4\% paraformaldehyde solution for 12 h. Frozen sections $(40 \mu \mathrm{m})$ were cut in the transverse plane and processed to reveal the transport of the biocytin with the use of a Vectastain ABC kit (Vector, Burlingame, Calif., USA). In all cases, the brain sections were collected in 6 compartments, and all sections were reacted and mounted on slides. The sections of the even-numbered compartments were counterstained with $1 \%$ neu- 
tral red to allow labeled fibers to be accurately located. The sections of the odd-numbered compartments were not counterstained, thus allowing the fine details of the transported biocytin to be visualized.

The animals slated for DiI (Invitrogen, Eugene, Oreg., USA) injection were first anesthetized with a tricaine methanesulfonate solution, then perfused with $0.1 \mathrm{M} \mathrm{PB}$ ( $\mathrm{pH} 7.4$ ), followed by a $4 \%$ solution of paraformaldehyde in $0.1 \mathrm{M}$ PB. The brains were exposed, and after postfixing for 3 days, they were removed from the skulls and blotted dry. Using an insect pin, a small cut was made into a given brain region, and crystals of DiI were then taken up on the tip of the insect pin and inserted into the cut. Ventral thalamic, preoptic, hypothalamic, and posterior tubercular injections of DiI were made after bisecting the brains into left and right halves in order to avoid laterally lying fiber tracts and to facilitate placement of the injections directly into the periventricularly located neuronal cell bodies. After application of the DiI crystals, the cut surfaces of the brains were covered in $10 \%$ gelatin in order to prevent the crystals of DiI from dislodging. The brains were then returned to a $4 \%$ buffered paraformaldehyde solution and stored in a dark oven at $40-42^{\circ} \mathrm{C}$. Following incubation times of 14-42 days, the brains were washed in PB for $12 \mathrm{~h}$, embedded in $10 \%$ gelatin, and fixed in a $4 \%$ buffered paraformaldehyde solution for at least 4 days. The blocked brains were sectioned at 50 $\mu \mathrm{m}$ using a vibratome, and the sections were counterstained with n-phenylenediamine following the protocol of Quinn and Weber [1988]. After counterstaining, the sections were mounted in Fluoromount (Southern Biotech, Birmingham, Ala., USA), a watersoluble mounting medium. An Olympus BH-Z fluorescence microscope was used to view the DiI and counterstained sections with rhodamine and FITC type filters, respectively. Representative sections were charted and photographed. The DiI photographs were inverted and balanced for contrast and brightness in Photoshop (Adobe, San Jose, Calif., USA).

\section{Results}

The results are reported in 3 sections: (1) the relative efficacy of the different tracers; (2) the connections of the dorsomedial telencephalic wall, and (3) the connections of the ventromedial telencephalic wall. The connections of the dorsomedial telencephalic wall and ventromedial telencephalic wall are illustrated in figures $2-4$ and 5-8, respectively. The connections of the selected brain centers (preoptic area, hypothalamus, and posterior tubercle) chosen for reciprocal experiments are illustrated in figure 9. The nomenclature follows that previously developed for lungfishes [Northcutt, 2009, 2011].

\section{Tracer Efficacy}

Each tracer and delivery method produced results (fig. 4A-C). Injections of BDA as a concentrated paste revealed far more retrogradely labeled cells and fibers than did iontophoretic injections, however. Injections of bio- cytin revealed connections similar to those resulting from both in vitro and in vivo BDA injections but did not retrogradely label any neurons outside the immediate injection site. Since in vitro injections of biocytin label only efferent fibers, however, these injections distinguished efferent from afferent connections related to a specific injection site (fig. 4B). Although injections of biocytin revealed approximately the same number of labeled fibers within the telencephalon as did the other tracers, the number of fibers so labeled diminished rapidly in the diencephalon, indicating that the brains of lungfishes are too large to effectively label long projections with in vitro biocytin injections. This was particularly obvious when the results from the biocytin injections were compared with those from DiI injections. Injections of DiI yielded far more retrogradely labeled cells and fibers, particularly outside of the telencephalon, than did any of the other tracers, regardless of delivery method. In the DiI experiments, longer incubation times ( 35 days) revealed the largest number of retrogradely labeled cells and fibers outside of the telencephalon. For these reasons, the results of DiI experiments were used to chart injections into the medial telencephalic wall, as well as injections into selected brain centers chosen for reciprocal experiments.

\section{Connections of the Dorsomedial Telencephalic Wall}

Injections of DiI (fig. 2B) into the dorsomedial telencephalic wall (the putative medial pallium) retrogradely labeled neurons in the internal granular layer of the ipsilateral olfactory bulb (fig. 2A), the dorsal pallium (fig. 2B), the lateral pallium (fig. 2E), and the medial amygdalar nucleus (fig. 2E). Reciprocal experiments that unilaterally labeled an olfactory bulb with BDA anterogradely labeled fibers in the ipsilateral putative medial pallium (fig. 4D), confirming that the putative medial pallium does receive secondary olfactory projections. Retrogradely labeled neurons are also seen in the ipsilateral putative medial pallium, ventral and caudal to the injection site (fig. 2B-D), as well as in the contralateral putative medial pallium (fig. 2B-D, $4 \mathrm{E}$ ).

Retrogradely labeled neurons also occur in the ipsilateral putative lateral septal nucleus (fig. 2A-C, 4F) and in the contralateral putative lateral septal nucleus and contralateral putative medial septal nucleus (fig. 2B-D). Injections of DiI into the putative septal nuclei (fig. 5C) labeled large numbers of fibers that ascend in the medial forebrain bundle to terminate within the intermediate segment of the putative medial pallium (fig. 4G, 5B), which confirms that one or more of the nuclei of the putative septum projects to the putative medial pallium. 


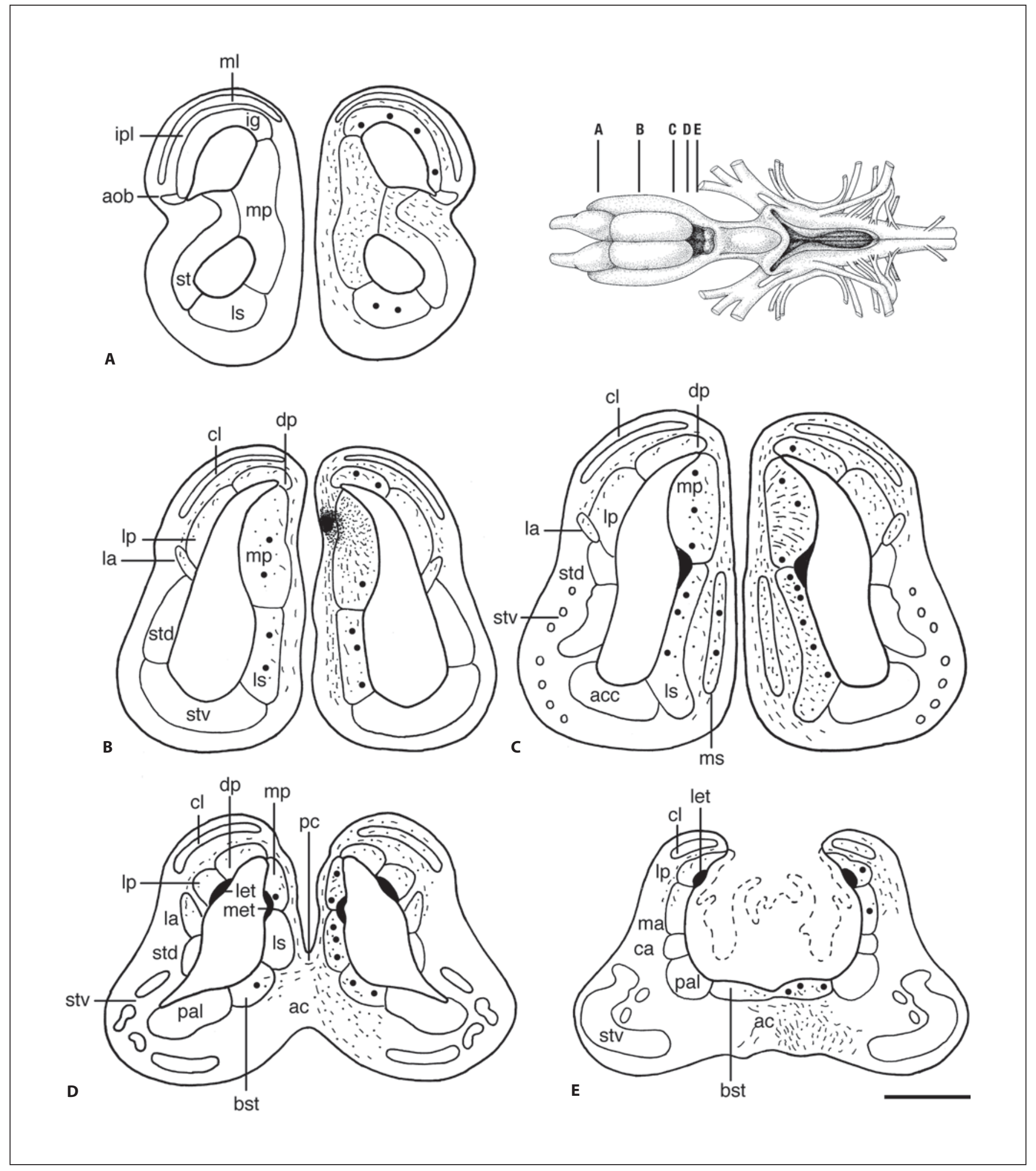

Fig. 2. Drawings of transverse sections through the telencephalic hemisphere (A-E) of the Spotted African Lungfish, charting the distribution of retrogradely labeled cells (large dots), labeled fibers (short lines), and terminals (small dots) following an injec- tion of DiI into the putative medial pallium (B). The relative positions of the sections are indicated on the drawing of the dorsal view of the brain located in the upper right corner of the figure. Scale bar $=1 \mathrm{~mm}$. 


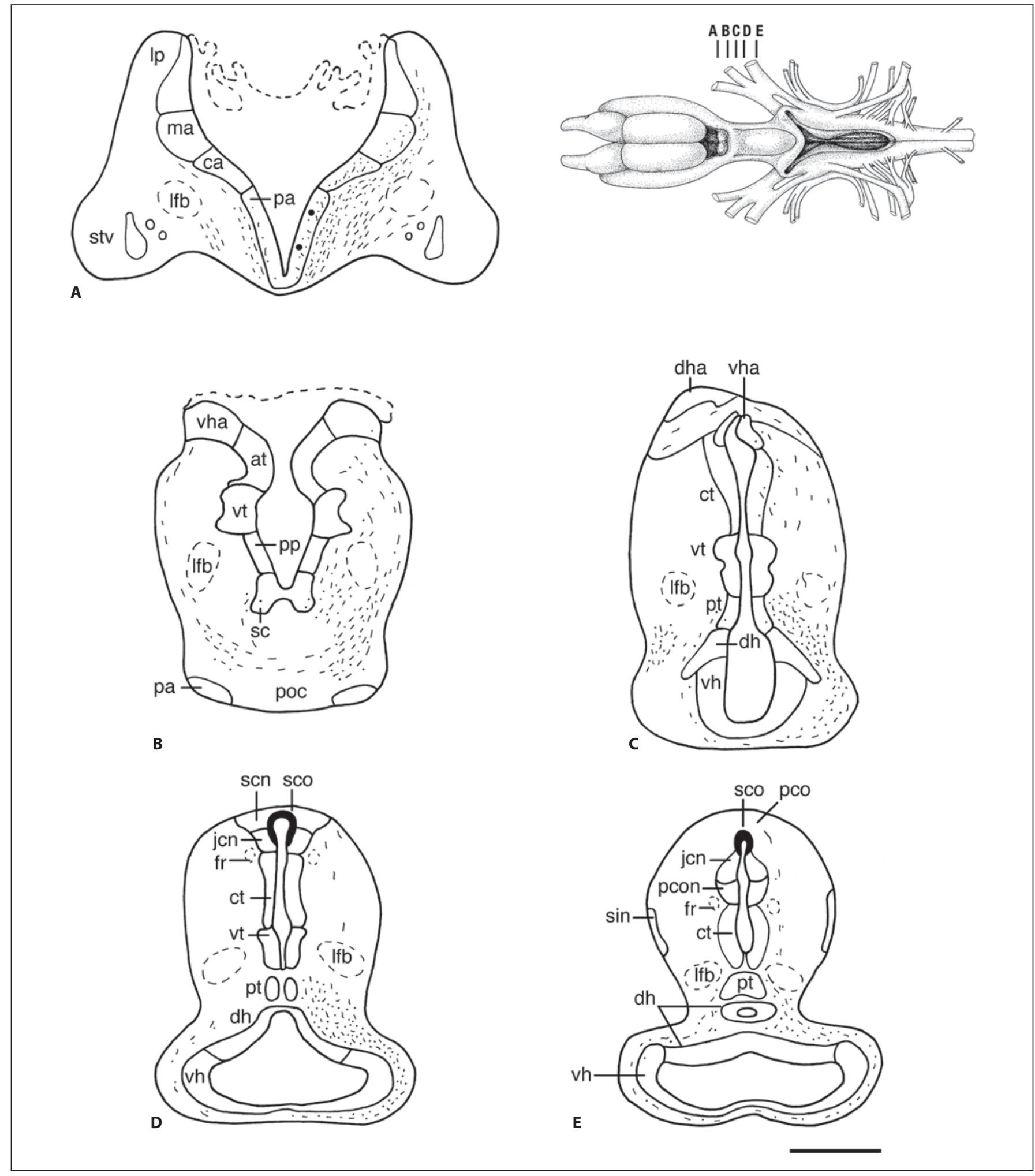

Fig. 3. Drawings of transverse sections through the telencephalon impar (A), the diencephalon (B, C), the pretectum (D), and the midbrain (E) of the Spotted African Lungfish, charting the distribution of retrogradely labeled cells (large dots), labeled fibers (short lines), and terminals (small dots) following an injection of DiI into the putative medial pallium (as indicated in fig. 2B). The relative positions of the sections are indicated on a drawing of the dorsal view of the brain located in the upper right corner of the figure. Scale bar $=1 \mathrm{~mm}$. 

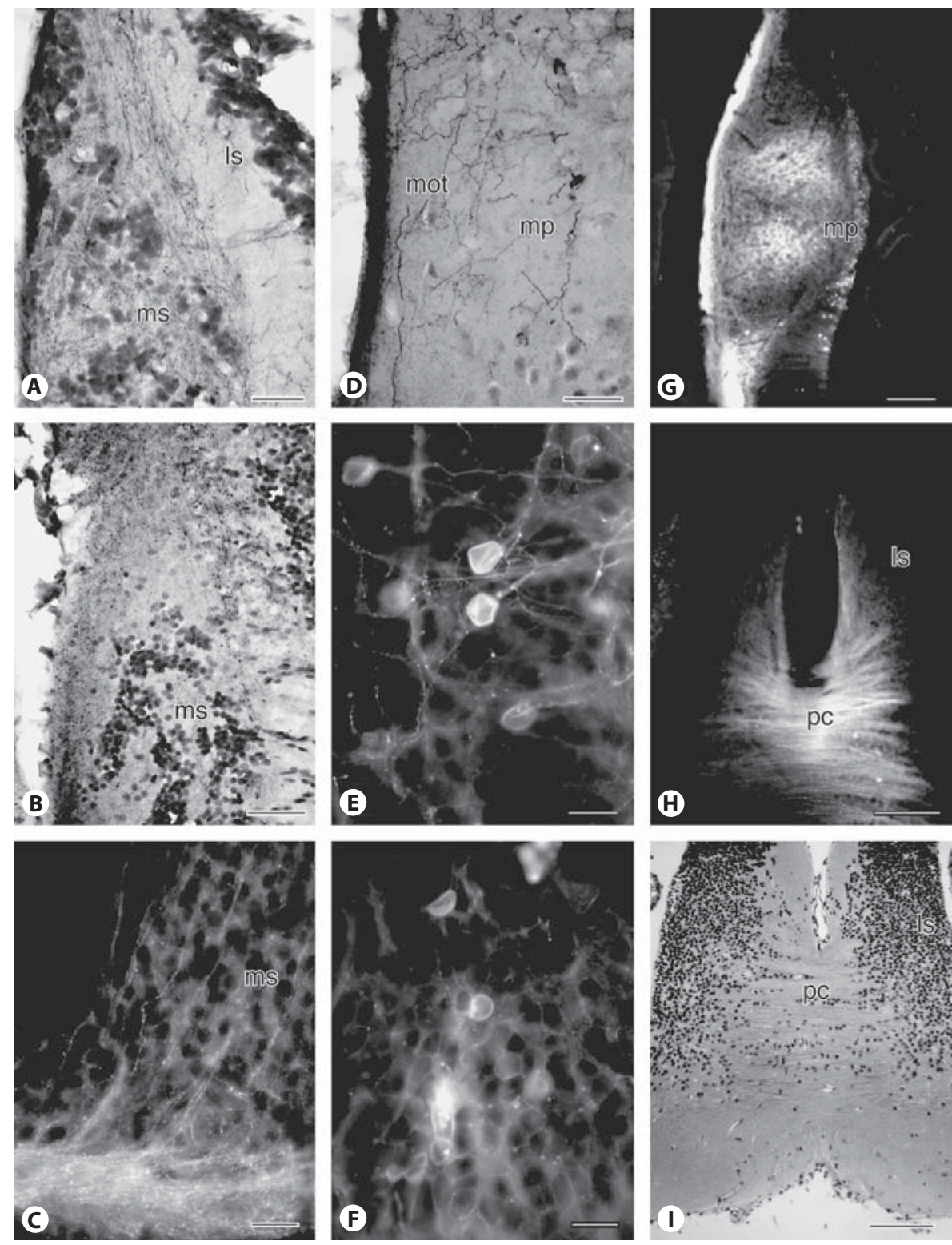

Fig. 4. Photomicrographs of retrogradely labeled cells, afferent and efferent fibers, and terminals following tracer injections related to the putative medial pallium of the African Spotted Lungfish. A Labeled fibers and terminals in the ipsilateral putative septal nuclei following an injection of BDA into the putative medial pallium. B Labeled efferent fibers and terminals in the ipsilateral putative septal nuclei following an injection of biocytin into the putative medial pallium. C Labeled fibers and terminals in the ipsilateral putative medial septal nucleus following an injection of DiI into the putative medial pallium. D Labeled fibers of the medial olfactory tract terminating in the ipsilateral putative medial pallium following a unilateral injection of BDA into an olfactory bulb. E Retrogradely labeled neurons in the contralateral putative medial pallium following an injection of DiI into the ipsilateral putative medial pallium. F Retrogradely labeled neurons in the ipsilateral putative lateral septal nucleus following an injection of DiI into the putative medial pallium. G Afferent fibers and their terminal field in the intermediate division of the ipsilateral putative medial pallium following an injection of DiI into the putative septal nuclei. $\mathbf{H}$ Labeled fibers in the pallial commissure following a unilateral injection of DiI into the putative medial pallium. I Transverse section through the pallial commissure and caudal putative lateral septal nucleus stained by the Bodian method. In each panel, dorsal and medial are to the top and left, respectively, except for $\mathbf{C}$, where dorsal and medial are to the left and bottom, respectively. In $\mathbf{H}$ and $\mathbf{I}$, dorsal is to the top, and the midline of the section occurs centrally. Scale bar $=20 \mu \mathrm{m}(\mathbf{E}, \mathbf{F}), 50 \mu \mathrm{m}(\mathbf{A}, \mathbf{C}, \mathbf{D})$, $100 \mu \mathrm{m}(\mathbf{B}), 200 \mu \mathrm{m}(\mathbf{H}, \mathbf{I})$, and $250 \mu \mathrm{m}(\mathbf{G})$. 

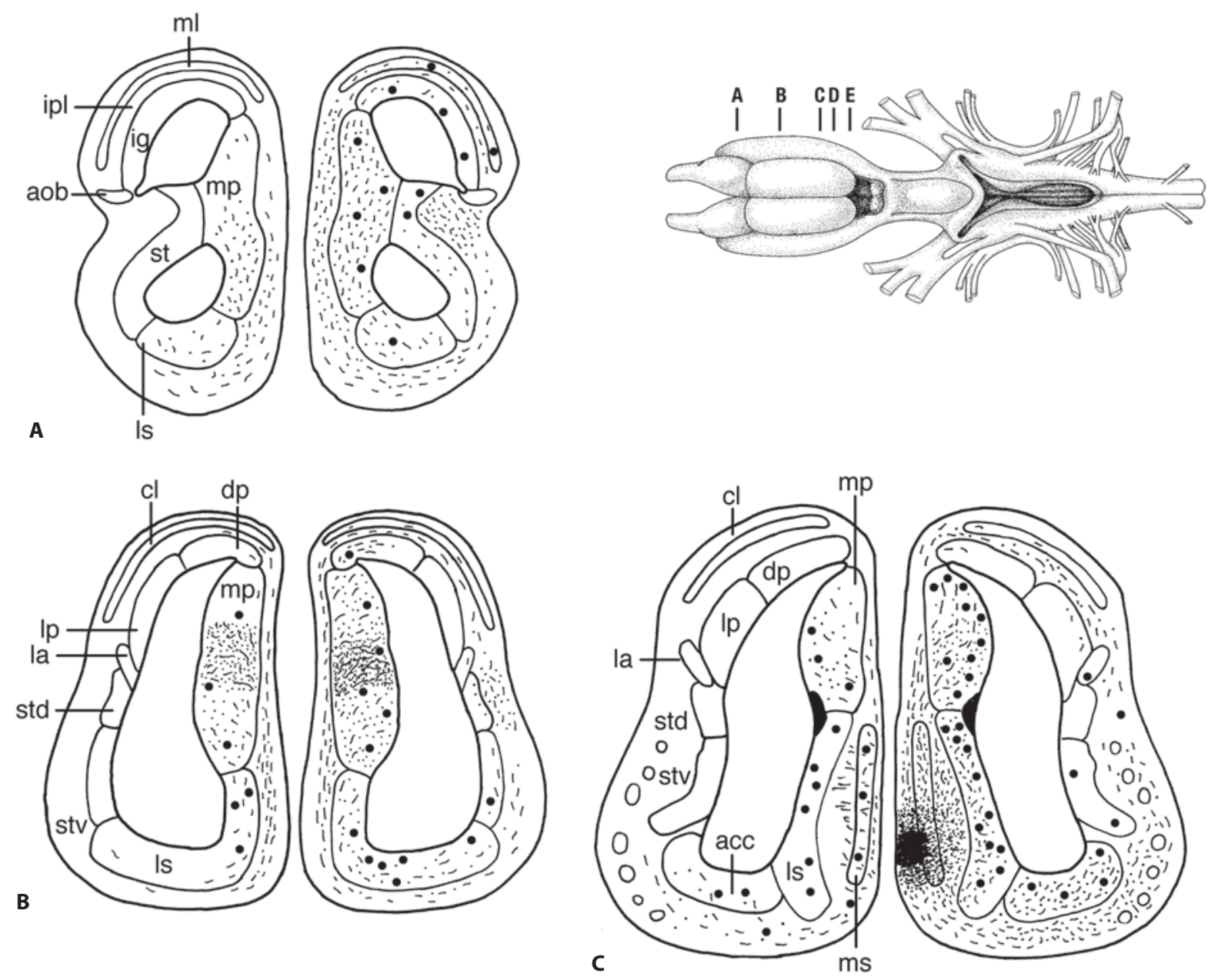

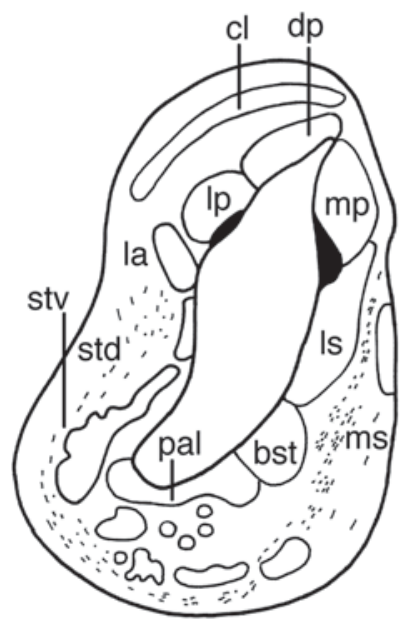

D

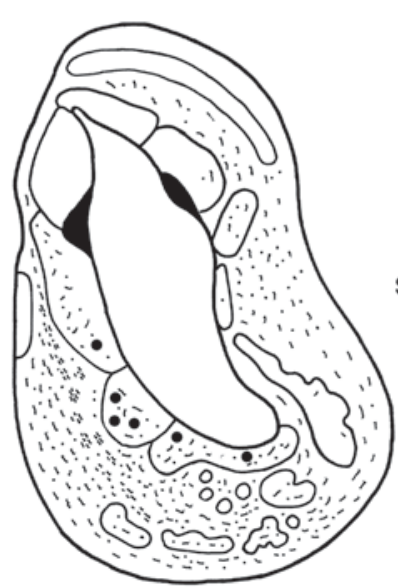

E

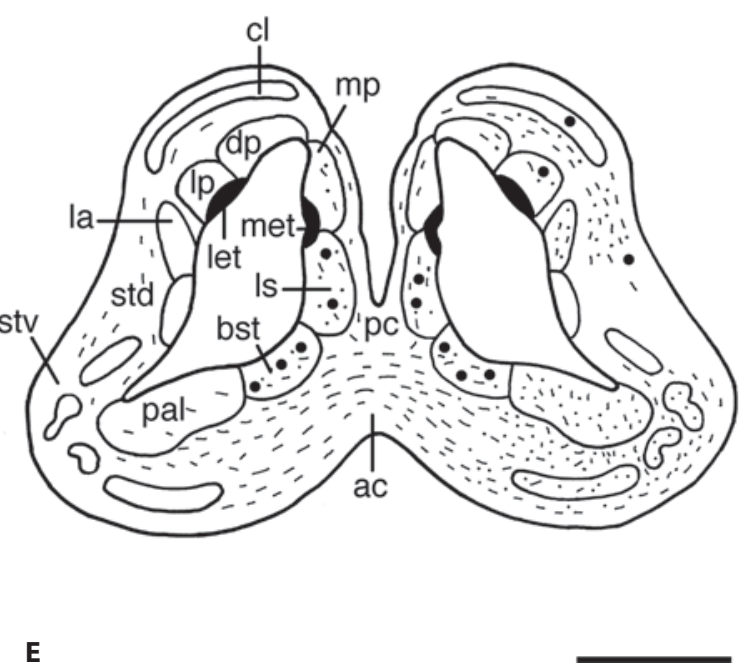

Fig. 5. Drawings of transverse sections through the telencephalic hemisphere (A-E) of the Spotted African Lungfish, charting the distribution of retrogradely labeled cells (large dots), labeled fibers (short lines), and terminals (small dots) following an injec- tion of DiI into the putative septal nuclei $(\mathbf{C})$. The relative positions of the sections are indicated on the drawing of the dorsal view of the brain located in the upper right corner of the figure. Scale bar $=1 \mathrm{~mm}$. 

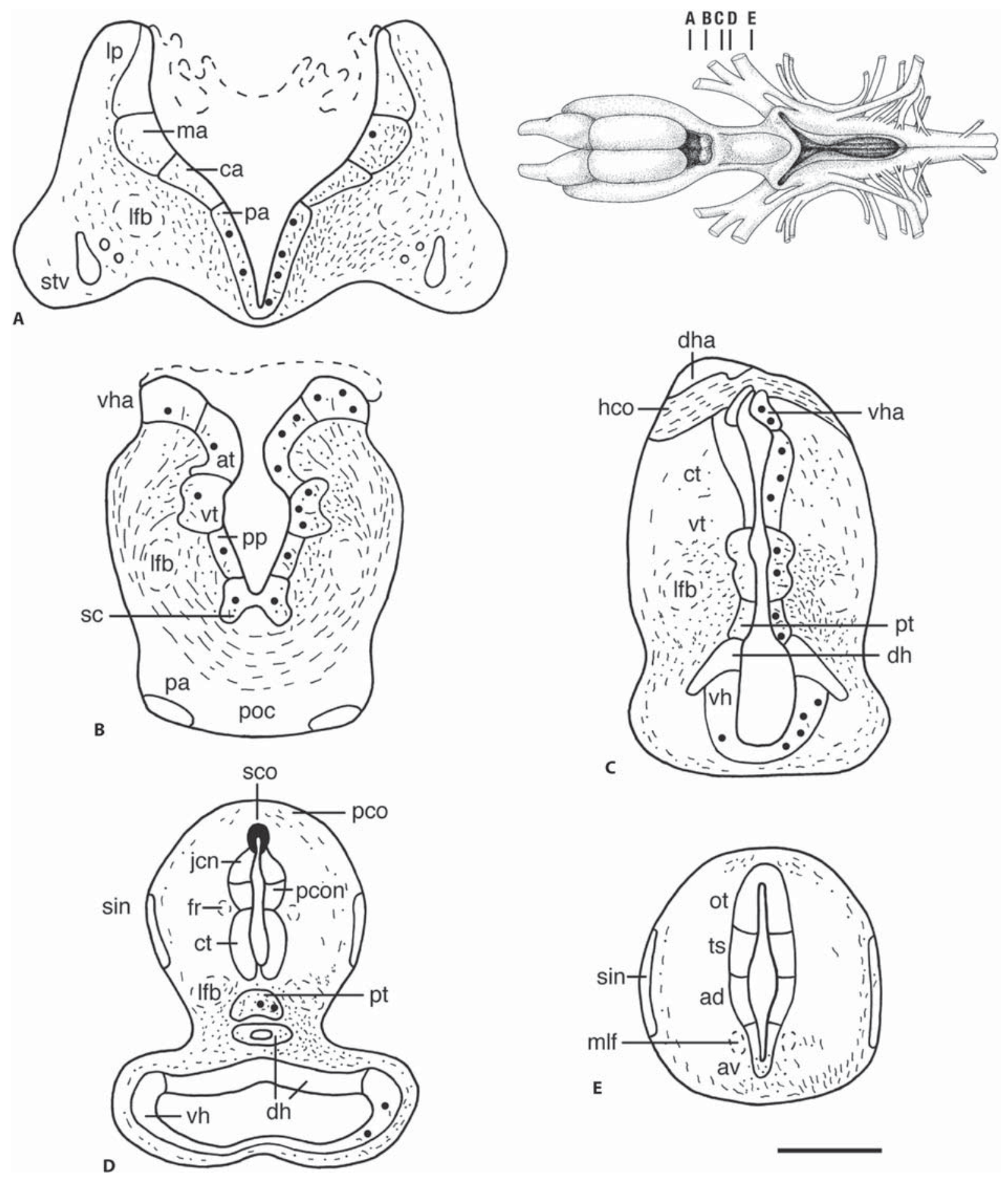

Fig. 6. Drawings of transverse sections through the telencephalon impar (A), the diencephalon (B, C), the pretectum (D), and the midbrain (E) of the Spotted African Lungfish, charting the distribution of retrogradely labeled cells (large dots), labeled fibers (short lines), and terminals (small dots) following an injection of
DiI into the putative septal nuclei (as indicated in fig. $5 \mathrm{C}$ ). The relative positions of the sections are indicated on a drawing of the dorsal view of the brain located in the upper right hand corner of the figure. Scale bar $=1 \mathrm{~mm}$. 
Fig. 7. Drawings of transverse sections through the caudal midbrain and isthmus (A, B) of the Spotted African Lungfish, charting the distribution of retrogradely labeled cells (large dots), labeled fibers (short lines), and terminals (small dots) following an injection of DiI into the putative septal nuclei (as indicated in fig. 5C). The relative positions of the sections are indicated on a drawing of the dorsal view of the brain located in the upper right corner of the figure. Scale bar $=1 \mathrm{~mm}$.

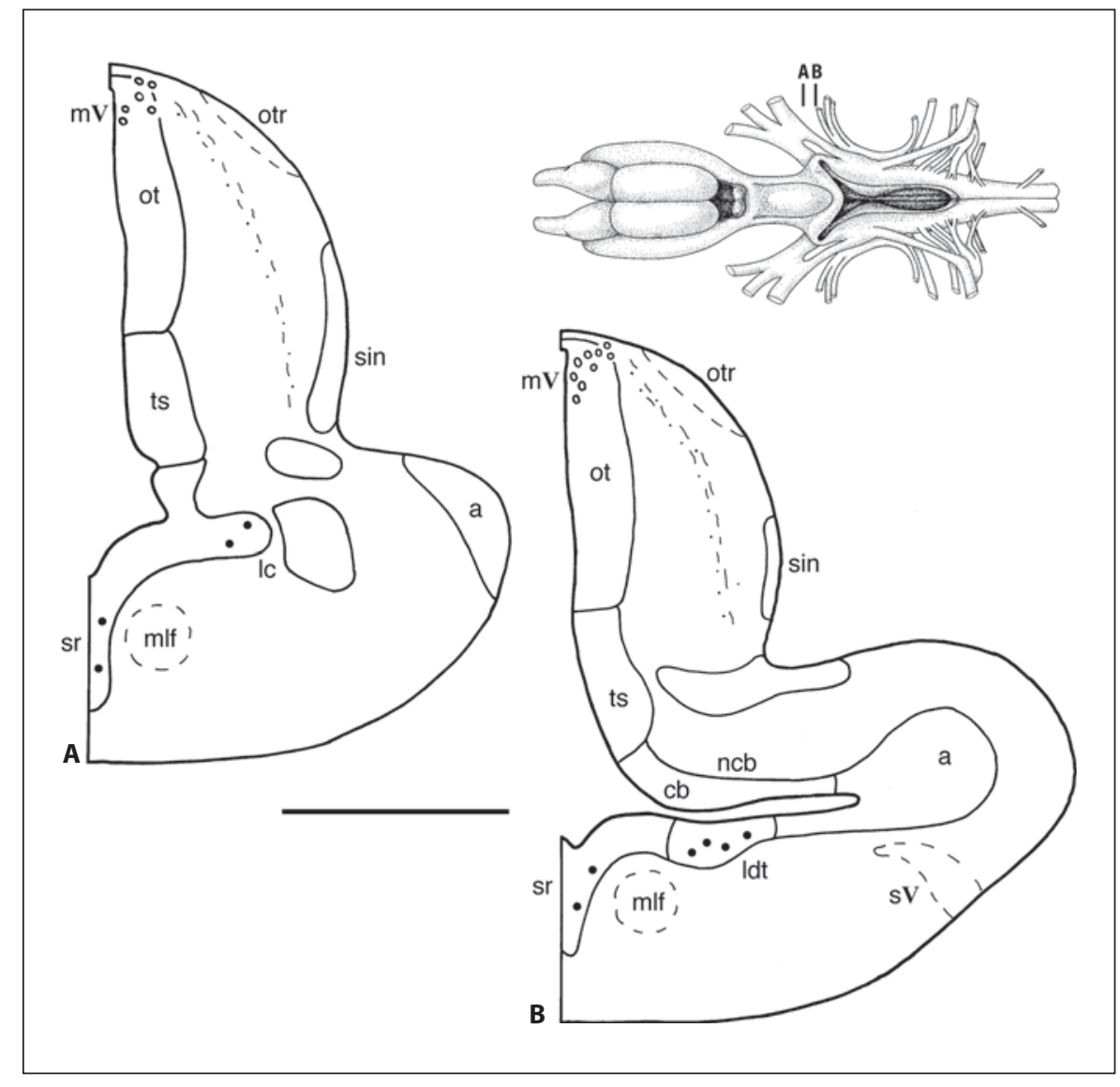

Retrogradely labeled neurons were also seen bilaterally in the bed nucleus of the stria terminalis (fig. 2D, E) and in the ipsilateral anterior periventricular nucleus of the preoptic area (fig. 3A). Reciprocal injections of DiI into the preoptic area confirm that a small number of fibers of the preoptic area do ascend and terminate ipsilaterally in the putative medial pallium (fig. 9A). Although no retrogradely labeled neurons were observed in the hypothalamic nuclei, multiple injections of DiI into the hypothalamus (fig. 9F) suggest that the ipsilateral putative medial pallium does received a sparse projection from one or more hypothalamic nuclei (fig. 9D).

Injections of DiI into the putative medial pallium (fig. 2B) labeled large numbers of fibers that generally followed either a dorsal or ventral course. Many of the labeled fibers could be traced dorsally and followed rostrally into the internal plexiform layer of the ipsilateral olfactory bulb (fig. 2A) or laterally and caudally into the ipsilateral dorsal pallium, lateral pallium, and the lateral and medial amygdalar nuclei (fig. 2B-E). Many of these labeled fibers appeared to be efferents from the putative medium pallium and/or the putative septal nuclei, as in many cases they could be seen to arborize and terminate in these various telencephalic centers. The in vitro biocytin injections into the medial telencephalic wall support this interpretation, as labeled fibers and terminals could be traced into the ipsilateral dorsal pallium, lateral pallium, and lateral and medial amygdalar nuclei. However, it is impossible to distinguish efferent fibers that originate in the putative medial pallium from efferent fibers that may arise in the putative septal nuclei, as these latter fibers pass dorsally through the putative medial pallium. Nonetheless, the larger number of fibers labeled in the ipsilateral dorsal and medial pallia following DiI injections into the putative medial pallium (fig. 2B-D), compared to those labeled in the putative septal nuclei (fig. 5B-E), suggests that both divisions of the medial telencephalic wall project to the ipsilateral pallium and amygdalar nuclei.

Following injections of DiI into the putative medial pallium, labeled fibers could also be traced ventrally (fig. 2B) and caudally (fig. 2C), and many were observed 

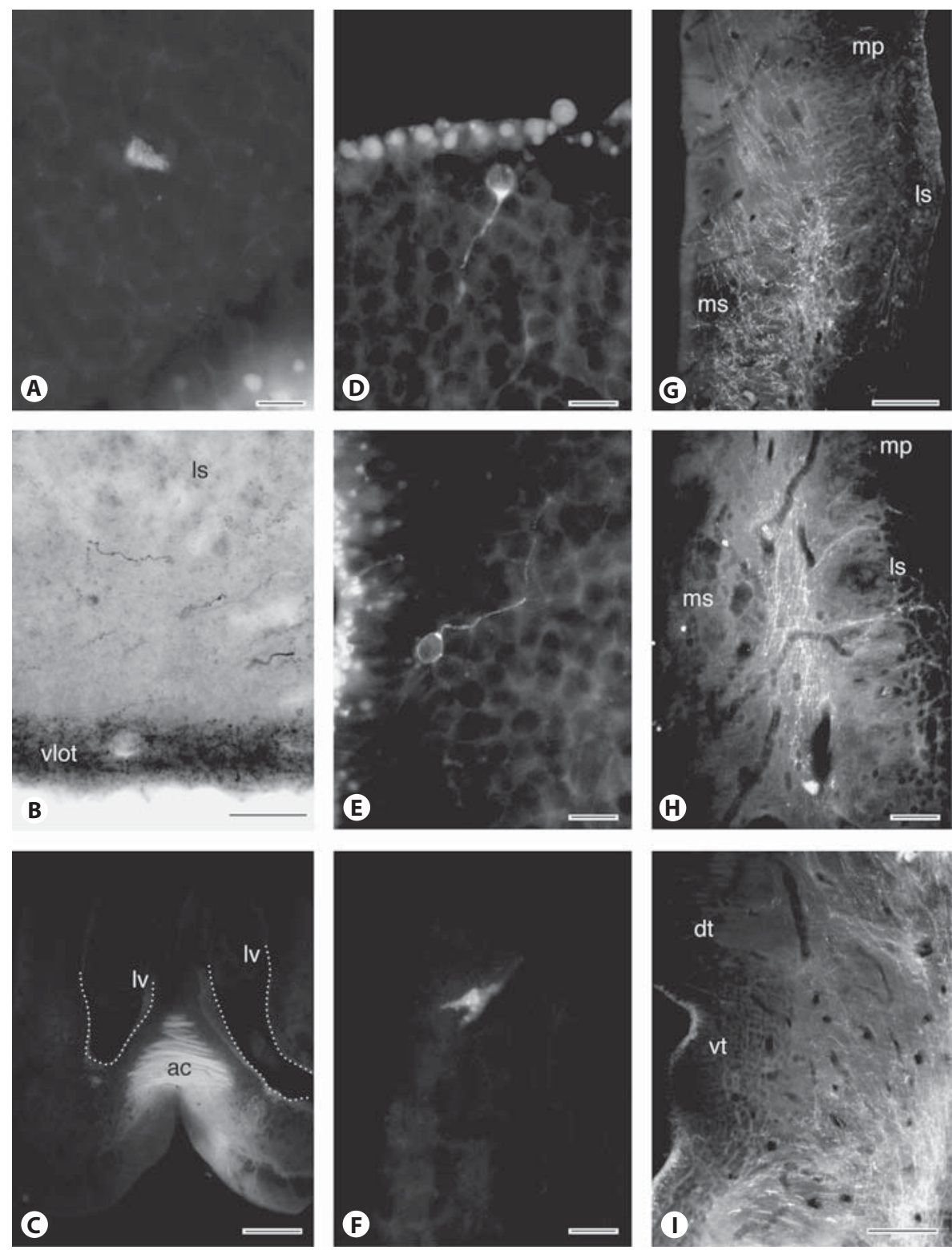

Fig. 8. Photomicrographs of retrogradely labeled cells, afferent and efferent fibers, and terminals labeled following tracer injections related to the putative septal nuclei of the Spotted African Lungfish. A Retrogradely labeled mitral cell in the ipsilateral olfactory bulb following an injection of DiI into the putative septal nuclei. B Labeled fibers and terminals in the ipsilateral putative lateral septal nucleus following an injection of BDA into the ipsilateral olfactory bulb. C Labeled fibers in the anterior commissure following a unilateral injection of DiI into the putative septal nuclei. D Retrogradely labeled neuron in the ipsilateral ventral thalamus following a unilateral injection of DiI into the putative septal nuclei. E Retrogradely labeled neuron in the ipsilateral ventral hypothalamus following a unilateral injection of DiI into the putative septal nuclei. F Retrogradely labeled neuron in the ipsilat- eral laterodorsal tegmental nucleus following a unilateral injection of DiI into the putative septal nuclei. G Labeled afferent and efferent fibers in the ipsilateral putative septal nuclei following a unilateral injection into the preoptic area. $\mathbf{H}$ Afferent and efferent fibers in the ipsilateral putative septal nuclei following a unilateral injection of DiI into the dorsal and ventral hypothalamus. I Afferent and efferent fibers in the ipsilateral dorsal and ventral thalamus following a unilateral injection of DiI into the putative septal nuclei. In each of the panels, dorsal and medial are to the top and left, respectively, except for $\mathbf{D}$, where dorsal and medial are to the right and top, respectively. In $\mathbf{C}$, the dotted lines mark the ventral halves of the lateral ventricles, and the midline of the section occurs centrally. Scale bar $=30 \mu \mathrm{m}(\mathbf{A}, \mathbf{D}-\mathbf{F}), 50 \mu \mathrm{m}(\mathbf{B})$, $100 \mu \mathrm{m}(\mathbf{H}), 200 \mu \mathrm{m}(\mathbf{I})$, and $400 \mu \mathrm{m}(\mathbf{C}, \mathbf{G})$. 


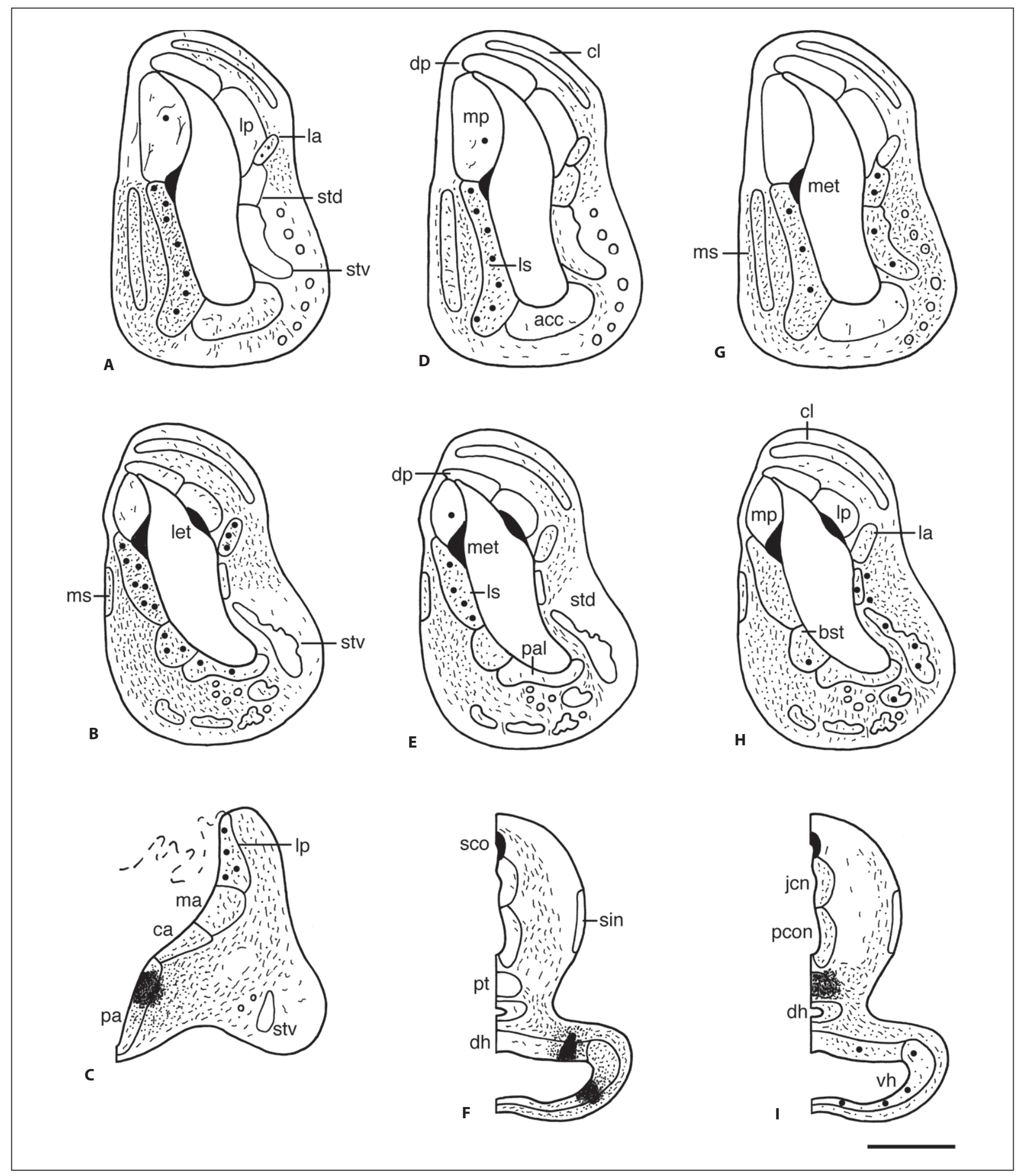

Fig. 9. Drawings of transverse sections through the telencephalon, the diencephalon, and the midbrain of the Spotted African Lungfish, charting the distribution of retrogradely labeled cells (large dots), labeled fibers (short lines), and terminals (small dots) following an injection of DiI into the preoptic nucleus (A-C), the hypothalamus (D-F) and the posterior tubercle $(\mathbf{G}-\mathbf{I})$. Scale bar $=1 \mathrm{~mm}$. 
to arborize, forming dense terminal fields in the putative lateral and medial septal nuclei (fig. 2C, D, 4A-C). Many of these labeled fibers were also seen to decussate in the palliall commissure (fig. $2 \mathrm{D}, 4 \mathrm{H}$ ) and then ascend to terminate in the contralateral putative medial pallium, dorsal pallium, lateral pallium, and lateral amygdalar nucleus (fig. 2D), or continue more rostrally to terminate in the putative lateral and medial septal nuclei, the putative medial pallium, and more lateral divisions of the pallium (fig. $2 \mathrm{~B}, \mathrm{C}$ ). The in vitro biocytin experiments, which labeled only efferent fibers, support this interpretation of the DiI cases.

The pallial and anterior commissures in the Spotted African Lungfish (fig. 4I) are not as clearly separated as those in tetrapods, but the pallial commissure is slightly more rostral than the anterior commissure and is separated from it by horizontally oriented rows of single cells, which appear to represent the caudal poles of the putative lateral septal nuclei and fuse within the rostral lamina terminalis (fig. 4I). The anterior commissure lies more ventral and caudal within the lamina terminalis.

The labeled fibers that did not decussate in the pallial commissure were seen to continue ventrally, and a number of them terminated in the bed nucleus of the stria terminalis (fig. 2D, E). Most of the labeled fibers, however, continued caudally to enter the medial forebrain bundle (fig. 2E), where they could be traced caudally and seen to terminate densely in the anterior periventricular preoptic nucleus (fig. 3A). Labeled fibers within the medial forebrain bundle continued caudally to terminate in the suprachiasmatic nucleus and, possibly, the posterior periventricular preoptic nucleus (fig. 3B). At this level, labeled fibers were seen to exit the medial forebrain bundle and could be traced dorsally into the anterior division of the dorsal thalamus (fig. 3B), as well as more caudally into the caudal division of the dorsal thalamus (fig. 3C) and the subcommissural pretectal nucleus (fig. 3D). A small number of labeled fibers were traced more caudally (fig. 3E) and appeared to terminate in the rostral optic tectum. Most of the labeled fibers in the medial forebrain bundle, however, continued caudally to terminate in the posterior tubercle and the dorsal and ventral hypothalamus (fig. 3C-E).

A number of the labeled fibers decussating in the pallial commissure (fig. 2D) did not turn dorsally to terminate in the contralateral pallium but were traced ventrally and caudally and were seen to terminate in the contralateral anterior periventricular preoptic nucleus and the suprachiasmatic nucleus (fig. 3B). At this level, a number of labeled fibers from the contralateral medial forebrain bundle appeared to decussate in the postoptic commissure and join the labeled fibers in the medial forebrain bundle that decussate more rostrally in the pallial commissure. The combined labeled fibers were traced caudally and dorsally and appeared to terminate in the ventral habenular nucleus (fig. 3B). A small number of labeled fibers that were seen to issue from the contralateral medial forebrain bundle decussate in the habenular commissure (fig. 3C) and also appeared to terminate in the ventral habenular nucleus.

\section{Connections of the Ventromedial Telencephalic Wall}

Injections of DiI (fig. 5C) into the ventromedial telencephalic wall (the putative septal nuclei) retrogradely labeled neurons in the internal granular layer and more superficially located mitral cells in the ipsilateral olfactory bulb (fig. 5A, 8A). Reciprocal experiments that labeled the ipsilateral olfactory bulb with BDA confirmed that the putative septal nuclei do receive secondary olfactory projections (fig. $8 \mathrm{~B}$ ). Retrogradely labeled neurons were also seen bilaterally in the putative medial pallium, the putative septal nuclei, and nucleus accumbens (fig. 5A-C). The DiI injections into the putative medial pallium (fig. 2B) support the contention that the putative septal nuclei do give rise to bilateral projections to the putative medial pallium. It is also possible that injections into the ventromedial wall interrupted fibers of passage from the contralateral putative septal nuclei as they ascend into the putative medial pallium. However, since injections into the ventromedial wall (fig. 5C) also labeled numerous fibers decussating in the anterior commissure (fig. 5E, 8C) and terminating in the contralateral putative septal nuclei (fig. 5B-E), it seems likely that the putative septal nuclei are interconnected by fibers that decussate in the anterior commissure. Since injections into the dorsomedial telencephalic wall did not retrogradely label neurons bilaterally in nucleus accumbens (fig. 2C), but injections into the ventromedial wall did so, it would appear that the putative septal nuclei do receive bilateral input from nucleus accumbens. This is also true for the dorsal division of the striatum and the pallidum. Injections into the dorsomedial telencephalic wall did not retrogradely label dorsal striatal or pallidal neurons (fig. 2BE), although injections into the ventromedial wall did retrogradely label neurons in the ipsilateral dorsal striatum and the pallidum (fig. 5D).

Injections of DiI into the putative septal nuclei (fig. 5C) also retrogradely labeled neurons bilaterally in the bed nuclei of the stria terminalis (fig. $5 \mathrm{E}$ ), the anterior periventricular preoptic nuclei (fig. $6 \mathrm{~A}$ ), the ventral habenu- 
lar nuclei, the anterior division of the dorsal thalamus, the ventral thalamus, the suprachiasmatic nuclei, the posterior periventricular preoptic nuclei, and the ventral hypothalamus (fig. 6B-D, 8D, E), as well as neurons in the ipsilateral medial amygdalar nucleus (fig. 6A), the caudal division of the dorsal thalamus, and the posterior tubercle (fig. 6C, D). Retrogradely labeled neurons were also observed in the superior raphe, locus coeruleus, and the laterodorsal tegmental nucleus (fig. 7A, B, 8F).

The retrogradely labeled neurons seen bilaterally in the bed nuclei of the stria terminalis following injections of DiI into the putative septal nuclei may result from the interruption of their axons as they pass into the medial wall to ascend into the putative medial pallium, as neurons are also retrogradely labeled following injection of DiI into the putative medial pallium (fig. 2D, E). However, a larger number of neurons were retrogradely labeled in the bed nuclei following injections into the ventromedial wall than injections into the dorsomedial wall, which suggests that the bed nuclei may project to both the putative septal nuclei and the medial pallium. Reciprocal injections of $\mathrm{DiI}$ into the anterior periventricular preoptic area (fig. 8G, 9A-C), the habenular nuclei, the dorsal and ventral divisions of the thalamus, the hypothalamus (fig. 8H, 9D-F), and the posterior tubercle (fig. 9G-I) confirmed that each of these neural centers projects heavily onto the putative septal nuclei.

As already described, DiI injections into the putative septal nuclei revealed a bilateral ascending projection that terminated as a dense field in the intermediate division of the putative medial pallium (fig. 4G, 5B). Ascending projections also appeared to continue more dorsally and laterally to terminate in the ipsilateral dorsal pallium, lateral pallium, and lateral amygdalar nucleus (fig. 5C). Unlike DiI injections into the dorsomedial telencephalic wall, DiI injections into the ventromedial wall labeled fibers that could be traced into the ipsilateral nucleus accumbens and the dorsal striatum (fig. 5C, D). Sparser projections were also seen to cross in the anterior commissure (fig. 5E) to terminate in the contralateral nucleus accumbens and the dorsal striatum (fig. 5C-E). These projections appeared to arise in the putative septal nuclei, as similar DiI injections into the dorsomedial wall did not result in labeled fibers projecting and terminating in nucleus accumbens and the dorsal striatum (fig. 2C-E).

Injections of DiI into the putative septal nuclei also revealed bilateral projections to the bed nuclei of the stria terminalis and the pallidum (fig. 5D, E). Similar descending projections were also observed following injections of DiI into the putative medial pallium, but the projections to the bed nuclei and the pallidum were both much heavier, particularly contralaterally, following injections into the putative septal nuclei as compared to injections into the putative medial pallium (fig. 2D, E, 5D, E).

Descending projections to the diencephalon and midbrain were similar following injections of DiI into either the putative medial pallium (fig. 3) or the putative septal nuclei (fig. 6, 7). However, the projections to the ipsilateral medial amygdalar nucleus (fig. 6A), the dorsal thalamus (fig. 6B, C), and the posterior tubercle (fig. 6C, D) were heavier following injections into the putative septal nuclei than the putative medial pallium. Two major differences in descending projections were noted, however. Injections of $\mathrm{DiI}$ into the putative medial pallium did not reveal a projection to the ventral thalamus (fig. 3B, C), whereas injections into the putative septal nuclei did reveal substantial descending bilateral projections to the ventral thalamus (fig. 6B, C, 8I). Similarly, descending projections to the caudal dorsal thalamus (fig. 6C) and pretectum (fig. 6D) were substantially heavier following injections into the putative septal nuclei than injections into the putative medial pallium. Finally, descending projections to the optic tectum (fig. 6E, 7) were much heavier following injections into the putative septal nuclei than into the putative medial pallium, and projections to the superficial isthmal nucleus and ventral tegmental nucleus (fig. 6E) were observed only following injections into the putative septal nuclei.

\section{Discussion}

The results are discussed in two sections: (1) the similarities and differences in the connections of the dorsomedial and ventromedial telencephalic wall in the Spotted African Lungfish compared with the connections of the medial pallium and septal nuclei in amphibians (table 2), which, along with other tetrapods, belong to the sister group of lungfishes; (2) the similarities and differences in immunohistochemical and other data on the medial wall in lungfishes and amphibians that bear on hypotheses of an extended pallium versus a restricted pallium.

\section{Connections of the Medial Telencephalic Wall}

In amphibians, there are marked differences in the afferents to the medial pallium and those to the septal nuclei, as well as major differences in the commissural connections of the medial pallium and the septal nuclei [Neary, 1990; Northcutt and Ronan, 1992]. In contrast the efferents of the medial pallium and the septal nuclei 
Table 2. Diagnostic differences in medial pallial and septal nuclear connections in amphibians

Afferent connections
Medial pallium receives
little input from preoptic area
no input from caudal dorsal thalamus
no input from ventral thalamus
little input from hypothalamus
no input from posterior tubercle
Septal nuclei receive substantial input from
preoptic area
caudal dorsal thalamus
ventral thalamus
hypothalamus
posterior tubercle

Commissural connections

Medial pallial connections via the pallial commissure

Septal nuclear connections via the anterior commissure

Efferent connections
Medial pallium
projects to striatum
does not project to the ventral thalamus
Septal nuclei do not project to striatum

[Neary, 1990; Northcutt and Ronan, 1992; Roth and Westhoff, 1999; Westhoff and Roth, 2002; Endepols et al., 2005; Roden et al., 2005; Roth et al., 2007] differ to a much lesser degree than do either the afferents or the commissural connections.

In amphibians, the medial pallium receives little input from the preoptic area, no input from the caudal dorsal thalamus, no input from the ventral thalamus, little input from the hypothalamus, and no input from the posterior tubercle. This is also true for the putative medial pallium in the Spotted African Lungfish. In contrast, the septal nuclei in amphibians receive substantial input from the preoptic area, the caudal dorsal thalamus, the ventral thalamus, the hypothalamus, and the posterior tubercle. This is also true for the putative septal nuclei in the Spotted African Lungfish.

In amphibians, most pallial interhemispheric connections decussate in the pallial commissure [Northcutt and Ronan, 1992; Roth and Westhoff, 1999; Westhoff and Roth, 2002], whereas the bulk of the interhemispheric connections, as well as the descending efferents of the septal nuclei, decussate in the anterior commissure [Neary and Northcutt, 1990; Endepols et al., 2005]. Although the separation of the pallial and anterior commissures in the Spotted African Lungfish is not as distinct as in amphibians, the same topographical relationships exist in lungfishes and amphibians. In both groups of vertebrates, the pallial commissure is the most dorsal commissure for decussation in the lamina terminalis, it is separated from the anterior commissure by several rows of subpallial cells that fuse across the midline, and the anterior commissure lies further ventral in the lamina terminalis and continues further caudal than the pallial commissure.

In the Spotted African Lungfish, the bulk of the interhemispheric connections in the dorsomedial telencephalic wall decussate in the pallial commissure, whereas the bulk of the interhemispheric connections in the ventromedial telencephalic wall decussate in the anterior commissure. These differences in commissural connections in the Spotted African Lungfish also support the hypothesis that the dorsomedial and ventromedial divisions of the medial hemispheric wall are homologous to the medial pallium and septal nuclei, respectively, in other vertebrates.

In amphibians, the medial pallium projects sparsely to the ipsilateral dorsal striatum [Neary, 1990; Roth and Westhoff, 1999; Westhoff and Roth, 2002], whereas the septal nuclei do not project to the dorsal striatum [Neary and Northcutt, 1990; Endepols et al., 2005]. In the Spotted African Lungfish, small injections of DiI into the putative medial pallium do label fibers and terminals in the ipsilateral rostral dorsal striatum (fig. 2A), but labeled fibers and terminals were found only in more caudal parts of the ipsilateral dorsal striatum following multiple injections of DiI along the rostrocaudal extent of the putative medial pallium. In contrast, all DiI injections into the putative septal nuclei revealed large numbers of labeled fibers terminating in the ipsilateral nucleus accumbens and, more sparsely, in the ipsilateral dorsal striatum (fig. 5B, C). It is possible that the labeled fibers observed passing through the neuropil of the ipsilateral dorsal striatum, following injections into the putative septal nuclei, do not terminate in the dorsal striatum but pass more dorsally to terminate in the lateral amygdalar nucleus. Such projections from the septal nuclei have been reported in amphibians [Endepols et al., 2005]. At present, however, the most conservative interpretation suggests that the putative septal nuclei in the Spotted African Lungfish, unlike the septal nuclei in amphibians, do project sparsely to the ipsilateral dorsal striatum.

Although Westhoff and Roth [2002] have reported spare interconnections between the medial pallium and ventral thalamus of amphibians, such connections have not been observed in other studies [Neary, 1990; Northcutt 
and Ronan, 1992]. In any case, there is no question that the septal nuclei and ventral thalamic nuclei in amphibians are massively interconnected [Neary and Northcutt, 1990; Endepols et al., 2005; Roden et al., 2005]. In this regard, the situation in the Spotted African Lungfish is identical to that in amphibians. Injections of DiI into the dorsomedial telencephalic wall failed to retrogradely label neurons in the ventral thalamus, and only a few labeled fibers were seen to pass through the neuropil of the ventral thalamus to terminate more dorsally in the dorsal thalamus (fig. 3B, C). In contrast, injections of DiI into the ventromedial telencephalic wall in the Spotted African Lungfish retrogradely label large numbers of neurons and result in substantial terminal fields in the ventral thalamus (fig. 6B, C). Thus, two of the three features that are diagnostic of efferent projections of the medial pallium and septal nuclei in amphibians are also seen in the efferent projections of the putative medial pallium and septal nuclei in the Spotted African Lungfish.

\section{Data Bearing on the Extended/Restricted Pallium Hypotheses}

Reiner and Northcutt [1987] presented immunohistochemical evidence, based primarily on the distribution of substance $\mathrm{P}(\mathrm{SP})$, that the medial hemispheric wall in the West African lungfish, Protopterus annectens, comprises dorsal and ventral divisions that are homologous to the medial pallium and septal nuclei, respectively, in other vertebrates with evaginated forebrains, thus supporting the hypothesis of an extended pallium originally proposed by Schnitzlein and Crosby [1967]. However, von Bartheld et al. [1990] challenged this report on several points and concluded that lungfishes have a restricted pallium. Each of these points has already been discussed and refuted [Northcutt, 2011] and will thus be considered only briefly here.

\section{Point 1}

Von Bartheld et al. [1990] misinterpreted a dorsocaudal thinning of the pallium as a tela choroidea, and therefore placed the interventricular foramen dorsal to the entire medial hemispheric wall, whereas Gerlach [1933] and Nieuwenhuys [1998] correctly described the interventricular foramen in a far more ventral position, as did Northcutt [2009, 2011].

\section{Point 2}

In amphibians, ependymal thickenings occur dorsally along the ventricular surface of the dorsal and medial pallia, as well as ventrally along the ventricular surface of nucleus accumbens. In lungfishes, however, ependymal thickenings occur laterally and medially, adjacent to the caudal lateral pallium and half way down the medial telencephalic wall (fig. 2D). Von Bartheld et al. [1990] concluded that these ependymal thickenings were homologous in amphibians and lungfishes, and that the medial ependymal thickening in lungfishes must indicate the border between the striatum and the septum. If this were the case, the position of the medial ependymal thickening in lungfishes would support the restricted pallial hypothesis. It has been shown, however [Northcutt, 2011], that the ependymal thickenings occupy identical positions in larval amphibians and lungfishes and only diverge in lungfishes with subsequent growth of the telencephalic hemispheres.

\section{Point 3}

Von Bartheld et al. [1990] noted that the cells of the hypothalamic paraventricular organ in lungfishes project to much of the medial hemispheric wall, which they believed must be septal, as the hypothalamus was not believed to project to the medial pallium in amphibians. Although hypothalamic projections to the medial pallium in amphibians had not been reported by 1990, they have subsequently been documented in the fire-bellied toad [Roth et al., 2004].

\section{Point 4}

Von Bartheld et al. [1990] noted that the medial pallium in amphibians receives only a sparse projection from the olfactory bulbs. They quoted Reiner and Northcutt [1987] as stating that the olfactory bulbs in Protopterus project to the dorsal and lateral pallium. They also noted that Reiner and Northcutt did not mention the medial pallium, and they apparently assumed that Reiner and Northcutt were denying projections to the medial hemispheric wall, which suggested to von Bartheld et al. that the entire medial hemispheric wall in lungfishes must be septal. As demonstrated in the present paper, however, injections of DiI into both divisions of the medial hemispheric wall in the Spotted African Lungfish do retrogradely label cells in the ipsilateral olfactory bulb, and reciprocal injections of DiI into the ipsilateral olfactory bulb label secondary olfactory projections to both divisions of the medial hemispheric wall, as they do in many vertebrates [Northcutt, 2006].

Point 5

Von Bartheld et al. [1990] claimed that the terminal nerve in amphibians projects to the septal nucleus but not 
to the medial pallium. Because the terminal nerve in lungfishes projects heavily to the medial hemispheric wall [von Bartheld et al., 1988], they concluded that the medial hemispheric wall in lungfishes is only homologous to the septal nuclei in other vertebrates. The terminal nerve does project to the medial pallium, however, as well as to the septal nuclei in elasmobranch fishes [Lovejoy et al., 1992] and in amphibians [Muske and Moore, 1994; Northcutt and Muske, 1994].

\section{Point 6}

As noted by von Bartheld et al. [1990], acetylcholinesterase (AChE) is high in the septal nuclei but low in the medial pallium in amphibians. They reported a band of AChE-positive fibers and terminals in the neuropil of the dorsal division of the medial hemispheric wall in Protopterus, which has been corroborated [Northcutt, 2009]. They claimed that this band of AChE demonstrates that the dorsal division of the medial hemispheric wall in Protopterus must be homologous to the septal nuclei in other vertebrates. However, their own study indicates, as does Northcutt [2009], that the concentration of AChE is much higher in the ventral division of the medial hemispheric wall of Protopterus, as it is also in the septal nuclei of amphibians [Northcutt, 1974]. Furthermore, injections of DiI into the dorsal and ventral divisions of the medial hemispheric wall in the Spotted African Lungfish indicate that the AChE-rich neuropil in the intermediate subdivision of the putative medial pallium is the target of cells in the putative septal nuclei and is most parsimoniously interpreted as an ascending septohippocampal pathway.

\section{Point 7}

Von Bartheld et al. [1990] claimed that the distribution of the chemical markers described by Reiner and Northcutt [1987] indicates that the medial pallial-septal border occurs at the dorsal edge of the medial hemispheric wall and that the entire medial wall must be interpreted as the septal nuclei. None of the chemical markers examined by Reiner and Northcutt [1987] and Northcutt [2009] provides an absolute marker for the pallium versus the subpallium. The relative distribution of substance $\mathrm{P}$ within the cerebral hemispheres in most vertebrates, however, provides a robust indicator of the subpallium. While it is true that moderate amounts of substance $\mathrm{P}$ do occur within the dorsal division of the medial hemispheric wall in Protopterus, the most intense expression of substance $\mathrm{P}$ occurs in the putative septal nuclei and striatum [Reiner and Northcutt, 1987; Northcutt, 2009].
The transcription factors ISL1 and NKX2.1 clearly delineate the subpallium from the pallium [Moreno et al., 2008]. Recently, the distribution of these transcription factors was reported in the Spotted African Lungfish and the Australian Lungfish [González and Northcutt, 2009], clearly confirming the pallial-subpallial borders recognized by Reiner and Northcutt [1987] and Northcutt [2009]. All available histochemical data thus supports the interpretation that only the ventral division of the medial hemispheric wall in lungfishes is homologous to the septal nuclei in tetrapods.

In summary, the connectional and immunochemical data, particularly the distribution of substance P, ISL1 and NKX2.1, strongly support the hypothesis that the dorsal and ventral divisions of the medial hemispheric wall in Protopterus are homologous to the medial pallium and septal nuclei, respectively, in tetrapods. If the dorsal division of the medial hemispheric wall is the homologue of the medial pallium in tetrapods, the hypothesis of an extended pallium is supported and the hypothesis of a restricted pallium must be rejected. The cerebral hemispheres in Protopterus are remarkably similar to those in amphibians, and this cytological and connectional pattern must have been present in the last common ancestor of lungfishes and amphibians. Furthermore, in both lepidosirenid lungfishes and amphibians, the medial pallium is the largest pallial division and may have expanded to mediate spatial learning. Highly developed spatial learning is widely documented in amphibians [Wells, 2007], and lepidosirenid lungfishes, particularly species of Protopterus, are very territorial and construct elaborate borrows [Greenwood, 1987; Mlewa et al., 2011]. Interestingly, the Australian lungfish, Neoceratodus, does not have an expansive medial pallium. Unfortunately, little is known about its behavior, but it has not been reported to be territorial [Kemp, 1987; Kind, 2011].

\section{Acknowledgements}

We thank Jo Griffith for assistance with the illustrations, Sue Commerford for literature retrieval and word processing, and Mary Sue Northcutt for help with many phases of the research and manuscript preparation. This work was supported by the US National Science Foundation (IBN-0919077), the German Academic Exchange Service (DAAD), and by private funding. 


\section{References}

Adams JC (1981): Heavy metal intensification of DAB-based HRP reaction product. J Histochem Cytochem 29:775.

- Brinkmann H, Venkatesh B, Brenner S, Meyer A (2004): Nuclear protein-coding genes support lungfish and not the coelacanth as the closest living relatives of land vertebrates. Proc Natl Acad Sci 101:4900-4905.

Clairambault P, Capanna E (1973): Suggestions for a revision of the cytoarchitectonics of the telencephalon of Protopterus, Protopterus annectens (Owen). Boll Zool 40:149-171.

Elliot Smith G (1908): The cerebral cortex in Lepidosiren, with comparative notes on the interpretation of certain features of the forebrain in other vertebrates. Anat Anz 33:513540.

-Endepols H, Roden K, Walkowiak W (2005): Hodological characterization of the septum in anuran amphibians. II. Efferent connections. J Comp Neurol 483:437-457.

Gerlach J (1933): Über das Gehirn von Protopterus annectens. Anat Anz 75:310-406.

González, A, Northcutt RG (2009): An immunohistochemical approach to lungfish telencephalic organization. Brain Behav Evol 74: 43-55.

Greenwood H (1987): The natural history of African Lungfishes; in Bemis WE, Burggren WW, Kemp NE (eds): The Biology and Evolution of Lungfishes, New York, Alan R Liss, pp 163-179.

-Holmgren N, van der Horst CJ (1925): Contribution to the morphology of the brain of Ceratodus. Acta Zool 6:59-165.

Kemp A (1987): The biology of the Australian lungfish, Neoceratodus fosteri (Krefft, 1870) in Bemis WE, Burggren WW, Kemp NE (eds): The Biology and Evolution of Lungfishes, New York, Alan R Liss, pp 181-198.

Kind PK (2011): The natural history of the Australian lungfish Neoceratodus forsteri (Krefft 1870); in Jørgensen JM, Joss J (eds): Biology of Lungfishes. Enfield, Science Publishers, pp 61-95.

- Lovejoy DA, Ashmead BH, Coe IR, Sherwood NM (1992): Presence of gonadotropin-releasing hormone immunoreactivity in dogfish and skate brains. J Exp Zool 263:272283.

Mlewa CM, Green JM, Dunbrack RL (2011): The general natural history of the African lungfishes; in Jørgensen JM, Joss J (eds): Biology of Lungfishes. Enfield Science Publishers, pp 97-127.
Moreno N, Domínguez L, Rétaux S, González A (2008): Islet1 as a marker of subdivisions and cell types in the developing forebrain of Xenopus. Neuroscience 154:1423-1439.

Muske L, Moore FL (1994): Antibodies against different forms of GnRH distinguish different populations of cells and axonal pathways in a urodele amphibian, Taricha granulosa. J Com Neurol 345:139-147.

Neary TJ (1990): The pallium of anuran amphibians; in Jones EG, Peters A (eds): Comparative Structure and Evolution of Cerebral Cortex. Cerebral Cortex, New York, Plenum Press, vol. 8A, part 1, pp 107-138.

Neary TJ, Northcutt RG (1990): Septal area connections in ranid frogs. Society for Neuroscience Abstracts, 16:129.

Nieuwenhuys R (1998): Lungfishes; in Nieuwenhuys R, ten Donkelaar HJ, Nicholson C (eds): The Central Nervous system of Vertebrates. Heidelberg, Springer, vol. 2, pp 936-1006.

Northcutt RG (1974): Some histochemical observations on the telencephalon of the bullfrog, Rana catesbeiana Shaw. J Comp Neurol 157: 379-390.

Northcutt RG (1984): Evolution of the vertebrate central nervous system: patterns and processes. Am Zool 24:701-716.

Northcutt, RG (1995): The forebrain of gnathostomes: in search of a morphotype. Brain Behav Evol 46:275-318.

Northcutt RG (2006): Connections of the lateral and medial divisions of the goldfish telencephalic pallium. J Comp Neurol 494:903-943.

Northcutt RG (2009): Telencephalic organization in the Spotted African Lungfish, Protopterus dolloi: a new cytological model. Brain Behav Evol 73:59-80.

Northcutt RG (2011): The central nervous system of lungfishes; in Jørgensen JM, Joss J (eds): Biology of Lungfishes. Enfield, Science Publishers, pp 393-445.

Northcutt RG, Muske LE (1994): Multiple embryonic origins of gonadotropin-releasing hormone $(\mathrm{GnRH})$ immunoreactive neurons. Dev Brain Res 78:279-290.

Northcutt RG, Ronan MC (1992): Afferent and efferent connections of the bullfrog medial pallium. Brain Behav Evol 40:1-16.

Quinn B, Weber E (1988): m-Phenylenediamine: a novel fluorescent Nissl-like stain for neuroanatomy. Soc Neurosci Abstracts 14:547.
Reiner AJ, Northcutt RG (1987): An immunohistochemical study of the telencephalon of the African lungfish, Protopterus annectens. J Comp Neurol 256:463-481.

Roden K, Endepols H, Walkowiak W (2005): Hodological characterization of the septum in anuran amphibians. I. Afferent connections. J Comp Neurol 483:415-436.

Roth G, Westhoff G (1999): Cytoarchitecture and connectivity of the amphibian medial pallium. Eur J Morphol 37:166-171.

Roth G, Laberge F, Mühlenbrock-Lenter S, Grunwald W (2007): Organization of the pallium in the Fire-Bellied Toad Bombina orientalis. I. Morphology and axonal projection pattern of neurons revealed by intracellular biocytin labeling. J Comp Neurol 501: 443-464.

-Roth G, Mühlenbrock-Lenter S, Grunwald W Laberge F (2004): Morphology and axonal projection pattern of neurons in the telencephalon of the Fire-Bellied Toad Bombina orientalis: an anterograde, retrograde, and intracellular biocytin labeling study. J Comp Neurol 478:35-61.

Rudebeck B (1945): Contributions to forebrain morphology in Dipnoi. Acta Zool 26:9-157.

-Schnitzlein HN, Crosby EC (1967): The telencephalon of the lungfish, Protopterus. J Hirnforn 9:105-149.

-Takezaki N, Figueroa F, Zaleska-Rutczynska Z, Takahata N, Klein J (2004): The phylogenetic relationship of tetrapod, coelacanth, and lungfish revealed by the sequences of fortyfour nuclear genes. Mol Biol Evol 21:15121524.

von Bartheld CS, Claas B, Münz H, Meyer DL (1988): Primary olfactory projections and the nervus terminalis in the African lungfish: implications for the phylogeny cranial nerves. Am J Anat 182:325-334.

von Bartheld CS, Collin SP, Meyer DL (1990): Dorsomedial telencephalon of lungfishes: a pallial or subpallial structure? Criteria based on histology, connectivity, and histochemistry. J Comp Neurol 294:14-29.

Wells KD (2007): The Ecology and Behavior of Amphibians. Chicago, University of Chicago Press.

Westhoff G, Roth G (2002): Morphology and projection pattern of medial and dorsal pallial neurons in the frog Discoglossus pictus and the salamander Plethodon jordani. J Comp Neurol 445:97-121. 